\title{
PERSPECTIVES
}

\section{Biofield Energy Healing from the Inside}

\author{
SARA L. WARBER, M.D., DEOGRACIA CORNELIO, M.A. JEREMY STRAUGHN, Ph.D., \\ and GAIA KILE, M.S.N., R.N.
}

\begin{abstract}
Objectives: Biofield energy healing involves controversial concepts, and although numerous controlled trials have evaluated the effects, little attention has been paid to the phenomenon from the perspective of the therapists themselves.

Design: Qualitative research.

Settings/location: Large Midwest metropolitan area. Interviews were generally conducted in the therapists' place of business.

Subjects: Experienced biofield energy therapists from several different disciplines.

Interventions: Indepth semistructured interviews, tape-recorded, transcribed verbatim, videotapes of demonstrations.

Outcome measures: We used a grounded theory approach to uncover relevant dimensions and themes related to the process of biofield energy healing.

Results: Major overall themes related to the "nature of energy" and the "healer-client relationship." Seven dimensions of the nature of energy include sources of energy, entities with energy, human energy anatomy, descriptions of energy, movement of energy, action of energy, and perception of energy. The dimensions build on one another to describe an energetic world view. The other major theme, the healer-client relationship, contains the central concept of healing facilitation as the goal of the experience. Compatibility and collaboration are critical to that process, as are creating a sense of trust and adhering to ethical standards. Communication underpins the whole process.

Conclusions: The biofield energy therapists share a common energetic world view, wherein they must surrender to a universal energy while simultaneously creating a therapeutic alliance with the client who is also an active agent in healing process. This understanding has the potential to alter our assumptions about research design in biofield energy healing.
\end{abstract}

\section{INTRODUCTION}

T The majority of patients who use alternative therapies do so in combination with conventional medicine (Astin, 1998). One area of alternative medicine that is particularly amenable to use in a complementary way is biofield energy therapy. Biofield energy therapists claim to manipulate the client's energy for the purpose of healing. This concept, as well as the existence of universal life energy itself, are neither embraced nor well understood by Western medicine. Despite studies on Therapeutic Touch (TT), qigong, and a few other modalities, little has been done to understand the underlying principles and terminology of biofield energy medicine from the perspective of the practitioners.

Biofield energy therapy includes several different modalities such as TT, healing touch, Reiki, and qigong. TT, ac-

University of Michigan, Michigan Integrative Medicine, Ann Arbor, MI. 
cording to Krieger (1993), is based on "The conscious use of one's hands to direct or modulate, for therapeutic purposes, selected nonphysical human energies that activate the physical body." A similar form of energy therapy is healing touch, which blends a number of energy techniques from various modalities, including TT. When organization in the energy field is disrupted and disease ensues, a healing touch practitioner aims to repattern the field (Umbreit, 2000). Reiki is a method for connecting the universal life force or energy with the body's innate powers of healing (Barnett et al., 1996). It is an energy therapy most commonly facilitated by light touch (Miles and True, 2003). Qigong, the Chinese terminology for energy healing, has been defined as a therapeutic practice that seeks to optimize and restore energy (qi) to the body, mind, and spirit (McCaffrey and Fowler, 2003).

Controlled trials of biofield energy therapies have tended to focus on the efficacy of TT. Warber et al. (1996) systematically reviewed the literature on controlled trials in the field of energy healing and its effects on general well-being, pain, anxiety, and stress. There was a moderate positive effect of energy healing across all primary outcomes. Other systematic reviews of research on TT reveal an ongoing debate over the validity and effectiveness of this "emerging" practice (Astin et al., 2000; Easter, 1997; Winstead-Fry, 1999). The power of well-designed clinical trials has not fully aided in validating energy healing because methodological challenges and flaws have rendered the results inconclusive.

Much like the controlled trials, qualitative studies have centered around TT and have focused on the treatment and its immediate effects rather than the underlying principles or nature of energy healing. Postpartum women report feeling relaxed, open, cared for, connected, as well as skeptical (Kiernan, 2002). TT helps intensive care patients to relax and brings them a sense of comfort and peace (Cox and Hayes, 1998) for others, it induces feelings of tingling, warmth, coolness calm and security (Hayes and Cox, 1999). Reiki is described as inducing a "liminal state" (Engebretson and Wendell, 2002).

So while a great deal of effort has gone into proving an effect of TT and patient perception of effect, little work has gone into exploring the meanings that energy practitioners assign the concepts of energy and the principles underlying energy healing. Thus, our primary objective was to explore relevant unifying concepts about the nature of energy healing that may underlie the different modalities through qualitative interviews with practicing biofield energy therapists.

\section{MATERIALS AND METHODS}

\section{Data collection}

Participants were selected to represent a variety of energy healing modalities from a midwestern U.S. metropolitan area. Based on general knowledge of energy healing, a theoretical sample was developed as subjects were purposively selected to include at least two therapists from key energy modalities. Primary energy healing modalities represented included Reiki, Healing Touch, Barbara Brennan School, Sufi Advanced Energy Healing, Therapeutic Touch Polarity therapy, Esoteric Healing, and qigong. The resulting sample of 19 biofield energy therapists included 13 women and 6 men. They ranged in age from 43 to 78, with an average age of 51. Fifteen (15) of the 19 therapists described their race or ethnicity as white, while 4 indicated nonwhite ethnicities or gave no answer. All but one had more than 3 years of experience, and $7(37 \%)$ had been practicing for more than 10 years. All participants completed a short demographic survey, an in-depth, semistructured interview and an optional demonstration of their healing technique on videotape.

\section{Data analysis}

The audiotaped interviews were transcribed verbatim. The resulting interview transcripts were then coded independently by three investigators using the content-analysis software package Atlas-ti ${ }^{\circledR}$ (Atlas.ti Scientific Software Development $\mathrm{GmbH}$, Eden Prairie, MN). The results of each investigator's coding were combined and systematized. Each major concept was then subcoded by a single investigator. The validity of these subcodes, the dimensions and relationships they represent were assessed against the primary data by a fourth independent investigator. Two other investigators viewed all videotapes and recorded similarities and differences in physical movements during the demonstrations.

The interview transcripts were coded for themes that were similar across all therapies as well those aspects which differed among them. Common thematic elements were grouped across interviews and hypotheses were generated about the common, underlying processes of biofield energy healing. Likewise, aspects that were dissimilar were identified and compared among interviews. Our theoretical constructs propose plausible relationships between these themes and concepts.

\section{RESULTS}

An overall gestalt of energy healing is one of healing facilitation. This takes place within a special relationship between two humans, the healer and the client, immersed within an energetic worldview. The relationship itself has several important dimensions that distinguish it from other therapeutic encounters. We first examine the "nature of energy" as described by the healers and then the "healer-client relationship" in order to begin to understand energy healing from the inside, through the accounts of the therapists themselves. 


\section{The nature of energy}

We categorized the therapists' utterances about healing energy into seven important dimensions: sources of energy, entities with energy, human energy anatomy, descriptions of energy, movement of energy, action of energy, and perception of energy (Table 1).

\section{Sources of energy}

Overall, healers are clear that the energy that they work with does not come from them personally. As one healer stated: "The universe is a construct of energies . . . our bodies are constructs of energies ..." Part of their work as healers is to manage themselves in such a way that they are attuned to this energy for healing. They purposefully connect to or become a conduit for the energy. They draw from the earth, the "universal energy field," or from God. In analysis of videos of the healers' demonstrations, there are very few commonalities in their physical movements in relation to the client, but they all share a moment within the session when they appear to be in a relaxing or receptive mode, often with eyes closed and hands upturned to receive. One healer clearly conveyed the principle which provides the basis for this openness: "Energy is universal energy . . p people have different names for it: universal, God, chi, ki. It is the spark of divinity. . . . I believe that we're all sparks of that consciousness, that divinity, and we have a connection to it."

\section{Entities with energy}

When we asked who has energy, the answers varied slightly from person to person, but the overall consensus was that all life forms have energy, including humans, animals, and plants. Other interviewees also identified crystals or mountains as having this energy. Some made a distinction, for example, of a chair not having an energy field, while others did not. Some talked of energy flowing through these entities or entities possessing an energy field. One said: "So I would say there is nothing but this energy, it's in all these different forms, you and me and the walls and the trees and the air."

\section{Human energy anatomy}

We wanted to understand more specifically about the energy associated with humans. We learned that the features of energy anatomy are unique to each individual: "Everybody has an energy pattern, just like they have fingerprints ..." Some describe the energy field or aura that surrounds a person and has layers that become less dense as you move away from the person. Some are able to see the layers as different colors: "I can oftentimes just see the very first, the etheric layer, which is very light, a very light, cloudy light." Others can feel the density of the layers: "As you move out between the etheric, the emotional, mental, causal, or spiritual layers, the energy moves faster and it's less dense." Some healers also identify certain areas of the body as hav-

Table 1. The Nature of Energy: Seven Dimensions

\begin{tabular}{|c|c|}
\hline Dimension & Examples \\
\hline Sources of energy & $\begin{array}{l}\text { "I do want to say that the energy that I use to heal is not my energy . . . ." } \\
\text { "The energy, myself, and God are all one." } \\
\text { "The energy is coming more from the larger cosmos." }\end{array}$ \\
\hline Entities with energy & $\begin{array}{l}\text { "Everyone possesses this, and as you explore these things within your own psyche, } \\
\text { your own self, then it sort of activates them." }\end{array}$ \\
\hline Human energy anatomy & $\begin{array}{l}\text { "There's a physical-mental-emotional-spiritual layers around you, right? So that you } \\
\text { can store physical problems, mental problems, spiritual, emotional problems, in } \\
\text { different areas." }\end{array}$ \\
\hline Metaphors for energy & $\begin{array}{l}\text { "So that I'm really working with an electrical charge. And it's this charge, then, that } \\
\text { emanates from me, from my heart, from my hands." } \\
\text { "Energy is light and it emanates, the energy emanates from inside ..." } \\
\text { "And I believe that it's love, that it's that simple ..." }\end{array}$ \\
\hline Energy movement & $\begin{array}{l}\text { "There's two ways to move an energy in our, in our experience, and that's, one way } \\
\text { is through getting to the core of the energy and then bringing love to it . . . and } \\
\text { that moves it out of the body. And the other way is through prayer work, by } \\
\text { saying prayers ..." }\end{array}$ \\
\hline Actions of energy & $\begin{array}{l}\text { "So the energies literally begin to shake and vibrate and then they open up with } \\
\text { radiator healing ... and basically it's somewhat imaginative ... but people also } \\
\text { know ... . what these energies are doing in their systems and in their bodies." }\end{array}$ \\
\hline Experience of energy & $\begin{array}{l}\text { "I get hot hands, my hands heat up, or I feel this holding around me. And I can } \\
\text { feel coolness and heat." } \\
\text { "You can sometimes hear it. If you're working on anything in the chest cavity down } \\
\text { you can actually hear bubbles . . you can hear gurgling and things like that." } \\
\text { "Sometimes [my hands will] feel a pressure, or almost like a knowingness, like a } \\
\text { sixth sense or something in my hand . . ." }\end{array}$ \\
\hline
\end{tabular}


ing a different quality of energy, for example, along meridians, or swirling in chakras, or focused along the central "hara line." The terminology used to describe this energy anatomy is grounded on the healers' training and background.

\section{Descriptions of energy}

Despite the culturally specific descriptions of the human energy anatomy, the concept of energy itself and the predominant descriptions of energy are often borrowed from the language of physics. For example, one said, "The energy, I believe, comes from the electromagnetic field. The positive and the negative ions that are within us, that cause our heart to function, to beat, the brainwaves to move and to help us think, our nervous system, all of these things are electromagnetic, and generate or manifest [energy]. ..." Another explained: "Matter doesn't exist without energy, matter is energy, you know, energy is matter, they're intertwined. And so if you remember that energy vibrating at a frequency creates matter, then you have to remember that there's things around the matter that can't necessarily be seen in our everyday walking and lives." Others used other terms from electromagnetic language to describe their experience including "electrical charge," "light," "vibration," and "sound waves." The language of science provides both a description of the physical mechanism that creates an energy field and a metaphor for the experience of energy.

The other major description of energy is as love or emotion: "I think love's a form of energy on all levels, whether it's . . . in that human form . . . having conditions around it, or if it's . . . in the divine love that we get in a very, very deep level." One healer described energy as spiritual.

\section{Energy movement}

In looking at quotes about the movement of energy, there are two important processes described. One process is the movement of energy through the therapist that seems to be directed from outside the therapist by the source of energy. An example is: "The energy comes in through my seventh or my crown chakra from God, and I do ask for God to give me that energy, through my heart chakra, and out my hands." This is even expressed in a negative statement: "But sometimes it doesn't seem as though a lot of energy flows." Another example: "The universe just does this, just funnels energy exactly and parallel to the way that the atmosphere and weather work around the globe, there's a constant interplay, a flux ...."

The other process described is movement of energy that is directed or transformed by the therapist and is involved in the healing process. This energy that the therapist moves might be the client's energy: "Any time it goes out of [their] energy field, you know energy cannot be destroyed but it can change forms, so it goes like from a puddle to a mist . . . [and movement of] your hand is out and away." The therapist might also be moving or directing the energy that flows through them as in the following quote which also gives an idea of how far such energy can be moved: "Because energy doesn't care if you're in the other room, next to, or across the ocean, you know, it's like electricity, it goes where you direct it." Another said: "Energy in a human system is just like electricity. If I put my hand on you and your energy is a little lower than mine, it's like a cascading effect . . . it'll cascade down until it's more even."

\section{Action of energy}

A question arises from the previous quotes: does energy have agency? In one quote the energy is identified by its abilities to act: "There's [energy] . . . for the healing of the psyche, there's one for healing of the whole body, the physical ... and then there's one that people use for distance healing." The following quote is an excellent example of energy acting: "This energy does have its own intelligence from the standpoint that I can be working on someone and I'll get to a particular place . . . and the amount of energy will increase ... it'll stay up at a higher level for however long or however much they're able to receive." In other instances it is clear that the therapist is assisting or using the energy to facilitate healing: "So what I do with the energy is to balance the [energy] fields and unblock the [energy] centers so that the body can heal itself."

\section{Experience of energy}

So how do the healers know about this energy that they work with, the universal energy or the client's energy? Although the healers have had training and education to temper their experience or their way of expressing the experience of energy, from their language it is clear that they have a personal experience of the energy that comes through their five ordinary senses and through extrasensory perception. A quote that combines these two ideas, as well as a little humility, is the following: "And I can see colors sometimes, but not always. I see best with my eyes closed. And I sometimes see visual images and sometimes deep in a healing I can see in the body, but not always." Another therapist described seeing an energy field this way: "I first saw my instructor's [aura], that red, and it does look like watercolors ... because . . . you can see through it, but you still see it very clearly." Still others described hearing and smelling energy. For others, it is a feeling of "heat," "tingling," or "holding." Yet another description of the divine energy pouring through the therapist was more kinesthetic: "It's like riding a river." One quote depicts the sensations the healer experiences and combines descriptions of the energy noted above: "Sometimes it feels like electricity running through you. Other times it might feel like . . . what love feels like. It's like the feeling that you get when you were holding a baby or when you're hugging your mother . . ."

The extraordinary senses these therapists use include 
clairgnosis (clear thinking), clairvoyance, a knowingness or a sixth sense, or an intuitive experience. One particularly moving quote follows: "I actually see with my heart, if you can stretch and believe that one. I actually run my physical eyes through my heart and can perceive the field that way ..."

\section{The healer-client relationship}

Beyond the purely energetic manipulation and exchange, there is a full interaction between healer and client, with characteristics and components of clear therapeutic value.

The expressed goal of the healer-client relationship is healing facilitation. This relationship is a collaborative process that is dependent on the compatibility of the healer and client. The process involves several forms of communication between them. Trust is needed for this healing facilitation to occur and ethics are important to the process (Fig. 1).

\section{Healing facilitation}

The healers describe the healing process as healing facilitation on 180 occasions throughout the 19 interviews. Quotes that represent central ideas are in Table 2. The healer is not the sole actor in this process but works with the energy and the client. The healers remain aware that they do not do the healing, in fact, the client must actively engage in the healing process. This is dependent on the state that each of them brings to the encounter. The healer seeks a state of surrender to enable the healing energy, however conceptualized, to do the healing work. The client must be in a state of openness, with a readiness to heal. According to these healers, this client state is far more important than whether the client believes in the treatment or not. Because the healer is human, part of their challenge is management of their own goals and the relationship.

\section{Compatibility}

An important concept that emerged about this relationship is that it must have an element of compatibility between

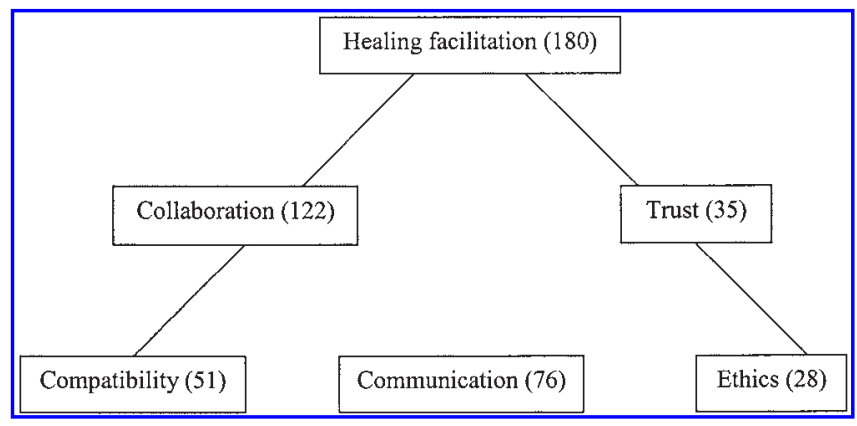

FIG. 1. Healer-client relationship. Conceptual map of major themes involved in the healer-client relationship. Numbers in parentheses indicate the number of quotes related to the concept.
Table 2. Elements of Healing Facilitation

Healer does not heal

Healer surrender

"I don't do any healing whatsoever, nor do I do any curing. I am totally there to facilitate the client's abilities to heal themselves. And I believe that with every atom in my body."

"This is powerful, it is a powerful thing, but it is not our power, it's not something that we possess. It is, it comes through us, it doesn't belong to us, and it is a gift."

Healer's goals

"So what we're doing as healers, no matter what your tradition is, is to try to bring that flow, that homeostasis back to the person, and an understanding."

Client action

"And I try to gently tell people, one, that is isn't my responsibility, and two, that this is energetic work, it is spiritual work, they're a participant, they're not a passive receiver, they're actually the active agent."

Client openness/readiness

"Because I think it so much depends on what they're ready for, what they're open for, what state their field is in."

the healer and client. In 19 quotes healers repeatedly emphasized the importance of connecting with the client. "But the thing I would emphasize is that the basis of healing is connection." Another manifestation of this was the 13 quotes about "being with" the client's state, for example, one said: "But to just be with him in the process of that illness and what was happening for him, and to be wherever he was each individual time he came." A special case of that concept was to be able to match energy levels with the client. "And so I pull my field in and I allow myself to feel the field of the other person with my field, and then I arrange my energy to meet theirs, at whatever level it is . .." Closeness may develop in the relationship but it was not necessary, nor was it a frequent occurrence.

\section{Collaboration}

In 40 instances the healers described healing as a two person process. The healer does something, and then the client does something. The process was described as a partnership as in the following quote: "So involving the patient, it's a partnership, it's not a one-way transfer of energy at all." Another important concept that was expressed in their language was that the healers were "working with" the client: "And after that, it's just literally begin to work with the client." 
Other special forms of collaboration were discussed including spiritual and energetic. One commented: "So it's really a partnership of our fields."

\section{Communication}

One might think that the relationship between the client and healer was conducted silently, but we found that communication plays an important role in the process (Fig. 2). Healers use communication to lay the groundwork for the healing encounter. They identify themselves, explain the process, and seek out information about the client. Some healers take a medical history, but many focus more on why the client is coming. Another finding was that some of the healers could get background information by sensing the client with their intuition or other abilities. The therapy itself often involved communication as when the healer asked for some client action or actually used dialogue as part of the therapy. Another form of communication included educating the client about their health and a special form we dubbed "soul talk" was exemplified by this quotation: "You relate to people behind their eyes, not just with our intellectual stuff or our words or our masks or our façade, but soul to soul." Communication was also important for sharing feedback. This could go both ways, the healer sharing what they have seen and the client explaining what happened to them during the session.

\section{Trust}

Because healers are human and have goals, it is important that they foster trust in the relationship. They do this by identifying their credentials, being honest, honoring the client: "I honor their defense mechanisms because that's how they've survived." Overall they try to create a setting within which the client feels safe: "They feel, I've had people say to me repeatedly, I feel safe. And that's not some-

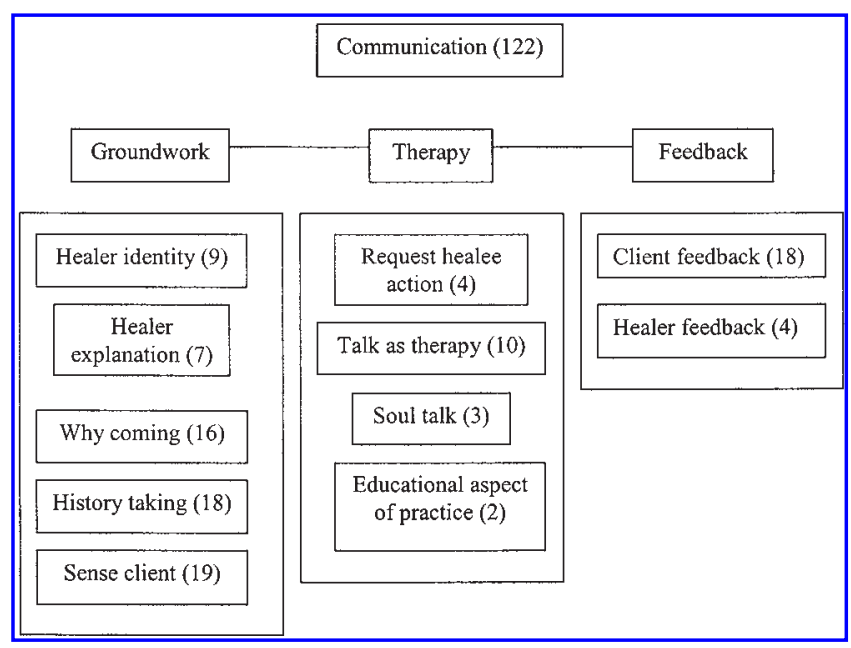

FIG. 2. Communication. Concepts related to the theme of communication and their attendant numbers of quotes. thing people feel on a regular basis. But in that time, right here, right now, in this healing situation, they feel safe." The healers too are vulnerable in this partnership, a concept that we found was closely associated with the openness which is central to their ability to heal: "I have a fair amount of empathetic response, and so then when I feel pain in my body it's not mine, it's the client's." They have to protect themselves in order to do the work.

\section{Ethics}

Ethical standards were identified at two levels. The first level relates to an emphasis on seeking permission to treat, being careful about touch, identifying a scope of practice and not being motivated by financial considerations: "And I think that it's really important to be ethical and to be centered and to take responsibility for your own stuff." The second deals with a need for the healer to take responsibility for their own emotions and motivations. Assuming the role of a healing facilitator means healing: "From a loving place instead of a sense of power." It also demands honesty and awareness of the client's vulnerability: "But generally, a lot of the people I work with can't see, so if you tell them you see something, they would believe you. So you could misuse that."

\section{DISCUSSION}

The overall picture we have elaborated is of a worldview where all material entities are energetic, possessing energy fields and certain specific channels of flowing or moving energy. The healer and client come together as energetic entities, each with a responsibility to engage in the process of healing. The healer has the additional responsibility of adapting him or herself to the client's current state and enhancing the connection between them. The healer taps into, or connects with the surrounding universal energy field. The universal energy flows through or into the healer. The healers then use their training to allow or modulate an improvement of the energy field of the client. This entire process enables the holistic healing of the client, potentially in mental, physical, spiritual, and emotional aspects of themselves.

Our work is consistent with other descriptions of the energy healing phenomenon (Barnett et al., 1996; Ireland and Olson, 2000; Krieger, 1993; McCaffrey and Fowler, 2003; Miles and True, 2003; Umbrett, 2000). Several important nuances are highlighted here, however. Our informants describe how they perceive energies with both their ordinary and extrasensory perceptions. One experiment (Rosa et al., 1998) showed that TT therapists were unable to sense the presence of an energy field. Our findings point toward the need to expand our notions about how that sensing might occur. 
Another important issue raised by our research is that of the healer-client relationship and its fundamental importance to the healing encounter. Healing facilitation does not take place in a silent procedural vacuum, but rather takes place within the context of a dyadic relationship that is managed on many levels by the therapist, including an energetic level, a psychological level, as well as a physical level. Furthermore, the healer is responsible for engendering trust, safety, and connection with the client. The connection is not just of materialistic humans in a room, but one in which the healer purposefully meets the client, energetically and psychologically, at their level and works with them to accomplish the desired healing. Another significant finding here expressed is that the client's state of readiness to heal is more critical than their belief in the process. This has important implications for the design of future research.

Limitations of our work include the one-sided nature of our information, that is, we have not interviewed clients about their perceptions of energy, the healing encounter, or the relationship. This is a focus of our ongoing work. We also have not brought healers of various disciplines together to see if they will generate commonly agreed upon principles and descriptions. Research using focus groups would strength and triangulate our findings. We have triangulated our analysis by using an iterative process wherein different analysts have coded the material and sought conflicting points of view.

\section{CONCLUSION}

We propose, at this stage in our analysis, that there is a coherent worldview expressed by energy healers that emanates from many cultural and disciplinary perspectives, and that describes the world in energetic terms. That description goes beyond our common Western notions of the electromagnetic nature of all life forms, and is based on the extrasensory perceptions of healers and the philosophies they have been taught. Furthermore, their ability to facilitate healing is intrinsically bound to their ability to formulate a connection with the client who is in a state of readiness to heal. Our current efforts focus on the preparation healers must go through to be ready for their work and further investigation of the clients' experiences. Creation of standardized scales that capture relevant characteristics of both healers, clients, and their relationships may make an important contribution to our ability to more accurately test the effectiveness of biofield energy therapies. The healers' descriptions of energy, energy fields, and its movements may inspire physicists and others to think of new ways to test the existence and change within these fields. Overall, the self-portrayal of energy healers evoked here is one of highly sensitive, attuned individuals operating, not as charlatans, but as ethical healing facilitators with specialized knowledge of the world just beyond our ordinary senses.

\section{ACKNOWLEDGMENTS}

The authors wish to acknowledge Andrea Kaye and Faye Harrington for their contributions in the production of this manuscript. This work was supported in part by a Robert Wood Johnson Clinical Scholars Fellowship and an American Academy of Family Physicians Advanced Research Training grant, held by Dr. Warber, as well as National Institutes of Health National Center for Complementary and Alternative Medicine grant number P50 AT00011.

\section{REFERENCES}

Astin J. Why patients use alternative medicine: Results of a national study. JAMA 1998;279:1548-1553.

Astin JA, Harkness E, Ernst E. The efficacy of "distant healing": A systematic review of randomized trials. Ann Intern Med 2000:903-910.

Barnett L, Chambers M, Davidson S. Reiki-Energy Medicine. Rochester, VT: Healing Arts Press, 1996.

Cox C, Hayes J. Experiences of administering and receiving therapeutic touch in intensive care. Complement Ther Nurs Midwifery 1998;4:128-132.

Easter A. The state of research on the effects of therapeutic touch. J Holistic Nurs 1997;15(2):158-175.

Engebretson J, Wardell D. Experience of a Reiki session. Altern Ther Health Med 2002;8:48-53.

Hayes J, Cox C. The experience of therapeutic touch from a nursing perspective. Br J Nurs 1999;8:1249-1254.

Ireland M, Olson M. Massage therapy and therapeutic touch in children: state of the science. Altern Ther 2000;6:54-63.

Kiernan J. The experience of therapeutic touch in the lives of five postpartum women. Am J Maternal Child Nurs 2002;27:47-53.

Krieger D. Accepting Your Power to Heal: The Personal Practice of Therapeutic Touch. Santa Fe, NM: Bear \& Company, 1993.

McCaffrey R, Fowler NL. Qigong practice: A pathway to health and healing. Holistic Nurs Pract 2003;17:110-116.

Miles P, True G. Reiki-Review of a biofield therapy history, theory, practice, and research. Altern Ther Health Med 2003;9:62-72.

Rosa L, Rosa E, Sarner L, Barrett S. A close look at therapeutic touch. JAMA 1998;279:1005-1010.

Umbreit AW. Healing touch: Applications in the acute care setting. AACN Clin Issues 2000;11:105-119.

Warber SL, Kile GL, Gillespie BW. "Energy" healing research. In: Jonas WB, Crawford CC, eds. Healing, Intention and Energy Medicine. Edinburgh: Churchill Livingstone, 2003:83-101.

Winstead-Fry P. An alternative review and meta-analysis of therapeutic touch research. Altern Ther 1999;5:58-67.

Address reprint requess to:

Sara L. Warber, M.D.

University of Michigan

Michigan Integrative Medicine

715 East Huron Street, Suite $1 W$

Ann Arbor, MI 48104-1555

E-mail:swarber@umich.edu 
This article has been cited by:

1. Catherine E. Kerr, Rachel H. Wasserman, Christopher I. Moore . 2007. Cortical Dynamics As A Therapeutic Mechanism for Touch HealingCortical Dynamics As A Therapeutic Mechanism for Touch Healing. The Journal of Alternative and Complementary Medicine 13:1, 59-66. [Abstract] [PDF] [PDF Plus]

2. 2005. LiteratureWatchLiteratureWatch. Alternative and Complementary Therapies 11:1, 51-52. [Citation] [PDF] [PDF Plus] 